\title{
Effects of tyrosine/phenylalanine depletion on electrophysiological correlates of memory in healthy volunteers
}

Citation for published version (APA):

Linssen, A. M. W., Riedel, W. J., \& Sambeth, A. (2011). Effects of tyrosine/phenylalanine depletion on electrophysiological correlates of memory in healthy volunteers. Journal of Psychopharmacology, 25(2), 230-238. https://doi.org/10.1177/0269881109348160

Document status and date:

Published: 01/02/2011

DOI:

$10.1177 / 0269881109348160$

Document Version:

Publisher's PDF, also known as Version of record

\section{Document license:}

Taverne

Please check the document version of this publication:

- A submitted manuscript is the version of the article upon submission and before peer-review. There can be important differences between the submitted version and the official published version of record.

People interested in the research are advised to contact the author for the final version of the publication, or visit the DOI to the publisher's website.

- The final author version and the galley proof are versions of the publication after peer review.

- The final published version features the final layout of the paper including the volume, issue and page numbers.

Link to publication

\footnotetext{
General rights rights.

- You may freely distribute the URL identifying the publication in the public portal. please follow below link for the End User Agreement:

www.umlib.nl/taverne-license

Take down policy

If you believe that this document breaches copyright please contact us at:

repository@maastrichtuniversity.nl

providing details and we will investigate your claim.
}

Copyright and moral rights for the publications made accessible in the public portal are retained by the authors and/or other copyright owners and it is a condition of accessing publications that users recognise and abide by the legal requirements associated with these

- Users may download and print one copy of any publication from the public portal for the purpose of private study or research.

- You may not further distribute the material or use it for any profit-making activity or commercial gain

If the publication is distributed under the terms of Article $25 \mathrm{fa}$ of the Dutch Copyright Act, indicated by the "Taverne" license above, 


\section{Effects of tyrosine/phenylalanine depletion on electrophysiological correlates of memory in healthy volunteers}

Anke MW Linssen, Wim J Riedel and Anke Sambeth

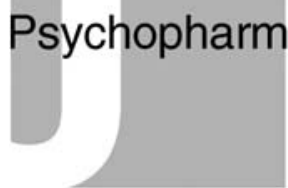

Journal of Psychopharmacology 25(2) 230-238

(C) The Author(s) 2011

Reprints and permissions:

sagepub.co.uk/journalsPermissions.nav DOI: $10.1177 / 0269881109348160$ jop.sagepub.com

\begin{abstract}
Dopamine is well known for involvement in reinforcement, motor control and frontal lobe functions, such as attention and memory. Tyrosine/ phenylalanine depletion (TPD) lowers dopamine synthesis and can therefore be used as a model to study the effects of low dopamine levels. This is the first study to assess the effect of TPD on memory performance and its electrophysiological correlates. In a double blind placebo (PLA)-controlled crossover design, 17 healthy volunteers (six males, 11 females) aged between 18 and 25 were tested after TPD and PLA. Working memory was assessed using a Sternberg memory scanning task (SMS) and episodic memory using the Visual Verbal Learning Test (VVLT). Simultaneously, event-related potentials (ERPs) were measured. The tyrosine and phenylalanine ratio was significantly reduced after TPD and increased after PLA. Working memory performance was not affected by TPD. However, ERP measures were affected by the treatment, indicating that TPD impaired stimulus processing during working memory performance. Episodic memory was not impaired after TPD. Again, alterations in ERP measures suggested adverse effects of TPD on memory-related processing. These results suggest that dopamine is involved in both working memory and episodic memory-related processing, although the effects are too small to be detected by performance measures.
\end{abstract}

@SAGE

\title{
Keywords
}

dopamine, tyrosine and phenylalanine depletion, working memory, episodic memory, event-related potentials

\section{Introduction}

Dopamine is one of the most thoroughly studied neurotransmitters. It is known to be involved in reinforcement and motor control (Nieoullon, 2002). In addition, evidence is accumulating that dopamine is likewise involved in cognitive function, including frontal lobe functions such as attention, planning and working memory (Cools and Robbins, 2004). Previous research has shown that in diseases in which dopamine transmission is altered, such as Parkinson's Disease, working memory is disturbed (Owen et al., 1997; Nieoullon, 2002). Dopaminergic treatment alleviates this problem (Costa et al., 2003; Lewis et al., 2005; Moustafa et al., 2008). Similarly, dopamine-elevating compounds improve working memory performance in healthy volunteers (Elliott et al., 1997; Luciana and Collins, 1997; Luciana et al., 1992). Administration of dopamine-lowering compounds, on the other hand, results in the impairment of working memory (Luciana and Collins, 1997; Mehta et al., 1999).

A way to study dopamine function is to acutely lower dopamine levels in the brain by depleting its precursors, tyrosine and phenylalanine (Barrett and Leyton, 2004). Because these amino acids are transported into the brain by neutral amino acid transporters, amino acids have to compete with each other. Lowering the relative amount of one or two specific amino acids worsens their position in this competition, which thereby leads to decreased availability of these precursors in the brain (Barrett and Leyton, 2004; McTavish et al., 2001). Indeed, there is evidence that Tyrosine/phenylalanine depletion (TPD) reduces dopamine release, dopamine synthesis and attenuates the induced elevation of dopamine levels (Bongiovanni et al., 2008; Le Masurier et al., 2004b; Leyton et al., 2004; McTavish et al., 1999; Montgomery et al., 2003). The effect of TPD is anatomically selective and preferentially affects dopamine-rich areas, such as caudate and putamen, while not affecting other regions, such as the frontal and cingulate cortex (Le Masurier et al., 2004a).

The findings with respect to various cognitive functions have been very inconsistent; some studies found effects of TPD lowering scores on spatial recognition and spatial working memory tasks (Gijsman et al., 2002; Harmer et al., 2001; Harrison et al., 2004; Nathan et al., 2002), whereas others did not (Ellis et al., 2007; Lythe et al., 2005; Mehta et al., 2005a), even though lower spatial working memory and planning accuracy scores were associated with decreased striatal dopamine levels (Mehta et al., 2005b). Furthermore, TPD impairs vigilance and sustained attention when combined with serotonin depletion (Matrenza et al., 2004), but TPD alone does not (Harrison et al., 2004). Grevet et al. (2002) found

Department of Neuropsychology and Psychopharmacology, Faculty of Psychology, Maastricht University, Maastricht, The Netherlands.

\section{Corresponding author:}

Anke MW Linssen, MSc, Maastricht University, Faculty of Psychology and Neuroscience, Department of Neuropsychology and Psychopharmacology, P.0. Box 616, 6200 MD Maastricht, The Netherlands

Email: anke.linssen@maastrichtuniversity.nl 
impaired performance on delayed recall in Rey's auditory verbal learning test (RAVLT) after TPD (Grevet et al., 2002), while Harrison et al. (2004) found no effect on a visual word-learning task.

More recently, TPD has been used to study the relationship between dopamine function and mood. It has been suggested that TPD induces a decrease in mood in healthy volunteers (Leyton et al., 2000; McLean et al., 2004; Ruhe et al., 2007). Furthermore, after TPD both healthy volunteers and recovered depressed patients display a higher sensitivity to negative words and a lower sensitivity to positive words in an affective Go/No-Go task (McLean et al., 2004; Roiser et al., 2005; Vrshek-Schallhorn et al., 2006).

Research on the relationship between dopamine and event-related potential (ERP) components is scarce. The available evidence, chiefly regarding $\mathrm{P} 300$, a component that is related to novelty processing and stimulus evaluation, is inconsistent (Coull, 1998; Farber et al., 2004; Prasher and Findley, 1991; Stanzione et al., 1991). For instance, P300 latency has been reported to be increased both in cases of enhanced and reduced dopamine transmission; delayed latency has been observed in PD and after administration of both dopamine antagonists and dopamine agonists (Prasher and Findley, 1991; Stanzione et al., 1991).

Because previous studies produced conflicting results with respect to the memory-modulating effects of altered dopamine transmission, this study aimed to further explore the effects of TPD on memory function, including working memory and episodic memory. This was done by measuring performance using the Sternberg memory scanning task (SMS) and a verbal learning task, and ERPs extracted from electroencephalography (EEG) recordings. To our knowledge, no study currently exists that has combined TPD and EEG during cognitive processing. Because working memory deficits have been observed after depletion of dopamine in PD, the intake of dopamine antagonists and TPD (Gijsman et al., 2002; Harmer et al., 2001; Harrison et al., 2004; Mehta et al., 1999; Nathan et al., 2002; Nieoullon, 2002), it was expected that depletion of tyrosine and phenylalanine would interfere with working memory function. Furthermore, it was hypothesized that TPD may disturb verbal learning (Grevet et al., 2002) and possibly enhance sensitivity to negative words.

\section{Method \\ Participants}

Twenty-two healthy volunteers aged between 18 and 25 years were recruited by means of advertisement posters at Maastricht University. Preselection occurred on the basis of pre-screening by telephone. The participants, without any presence of psychiatric and neurologic diseases, were subjected to a medical screening by means of a medical questionnaire. Inclusion criteria were normal binocular activity (corrected or uncorrected), a body mass index between 18.5 and 30 and signed informed consent.

Exclusion criteria were a history or presence of mental or physical disorders, such as cardiac, hepatic, renal, pulmonary, neurological gastrointestinal, haematological or psychiatric illnesses, and sensory or motor deficits that could affect test performance. Furthermore, participants were excluded if they were pregnant or lactating, in the case of drug abuse, when drinking more than 20 alcoholic beverages a week or more than five caffeine-containing beverages a day.

Five participants did not complete the study because they had to vomit after intake of the amino-acid drink. The 17 participants (11 females, six males) who completed this study had a mean age of 21.1 years $(\mathrm{SD}=2.0$ years).

The study was approved by the ethical committee of Maastricht University and conducted in accordance with the ethical principles that have their origin in the Declaration of Helsinki 1975, revised Hong Kong 1989.

\section{Design}

The study was conducted according to a double-blind, placebo (PLA)-controlled, three-way crossover design. The three testing sessions were spaced apart by a period of at least one week. On one occasion participants received a balanced amino acid drink (PLA). On the other two occasions they received an amino acid drink either lacking tyrosine and phenylalanine (TPD) or histidine (HID, as part of a larger research study (van Ruitenbeek et al., 2009)).

\section{Procedure}

The study was integrated in a larger study on the influence of TPD and HID on the brain and behaviour. This section describes the procedure of the complete study.

Participants were not allowed to use drugs or medication, except oral contraceptives, within two weeks before the first test-day until the end of the study. The participants were instructed to arrive at the lab in a fasted condition. Furthermore they were requested to abstain from alcohol and caffeine from 9:00 p.m. the night before. Testing days started at either 8:30 a.m. or 10:30 a.m. A catheter was placed in order to collect blood samples, which were used to verify if depletion was successful. Blood samples were obtained at $0,2,4,6$ and 7 hours. After the first blood sample was collected, participants completed two questionnaires: Bond $\&$ Lader and the complaint list. Subsequently participants received the amino acid drink, which had to be consumed within 15 minutes. This was followed by a break in which participants could consume water or caffeine-free tea. After three hours the participants had lunch. The lunch consisted of three slices of gluten-free bread with honey, apple treacle or jam, an apple and a caffeine-free soda drink.

Four and half hours after consumption of the drink, the EEG cap was placed. EEG recording started five hours after consumption of the drink with four minutes baseline measurement, two minutes with eyes open and two minutes with eyes closed. Thereafter, the participants were subjected to a test battery of approximately 90 minutes (with a 10 minute break in between), consisting of the following tests: the Visual Verbal Learning Test (VVLT), Critical Tracking Task, SMS: delayed recall and delayed recognition, Choice Reaction Time task, Simple Reaction Time task and an Oddball paradigm. In this study only the SMS and the VVLT are of interest. After completion of the test battery 
the baseline EEG measurement was repeated. After the last blood sample was taken, the catheter was removed and the participants completed the mood questionnaire and the complaint list a second time.

\section{Material}

Drink composition: The quantities of amino acids in the mixture, as given to male participants, were based on those used by Young et al. (1985). Female participants received $85 \%$ of this amount based on their average lower body weight (Ellenbogen et al., 1996). The content of the TPD mixture was the same as the balanced drink, except that it lacked tyrosine and phenylalanine. The amino acids were solved in $200 \mathrm{ml}$ (for males) or $170 \mathrm{ml}$ (for females) water.

Blood samples: Blood samples were collected via a catheter placed in the participants' dominant arm. After collection of the blood, the catheter was cleaned with heparin and the blood samples were centrifuged for five minutes at $4{ }^{\circ} \mathrm{C}$ (at $4000 \mathrm{rpm}$ ). Subsequently, $1 \mathrm{ml}$ of plasma was stored at $-20^{\circ} \mathrm{C}$ until performance of the amino acid analysis (van Eijk et al., 1993). The dependent measures were the percentage of change from $\mathrm{T} 0$ to $\mathrm{T} 7$ in both tyrosine and phenylalanine plasma levels and the tyrosine and phenylalanine/ $\Sigma$ LNAA ratio.

Questionnaires: Two questionnaires were used to assess mood: the Bond \& Lader Visual Analogue Scale (VAS) and the complaint list. The VAS required participants to score bipolar items by marking a $100 \mathrm{~mm}$ line, with a normal state being indicated by marking the middle of the line. The dependent measures were total scores, measured in millimetres, on three dimensions: alertness, contentment and calmness. On the complaint list participants had to indicate, on a scale from 0 to 3 , to what extent they experienced the presented complaints, including for example nausea, headache and feeling cold. The dependent measure was the total score summed over the 31 items.

\section{Tasks}

SMS: The memory scanning task (Sternberg, 1966) was used as a measure of working memory. In this task the participants were required to memorize one, two or four consonants. After memorization, 48 consonants were presented and the participants were required to indicate if the presented items appeared in the memorized sequence. The stimuli were presented in six blocks of 48 items each. In the first three blocks the workload increased, so participants had to memorize one letter in the first block, two letters in the second and four letters in the third block. In the fourth, fifth and sixth block this order was reversed. In this task reaction time increases linearly with the workload; that is, the number of items that has to be held in memory. The slope of this function is an indication of the speed of scanning of short-term memory, whereas the intercept is a measure of psychomotor speed. The behavioural-dependent measures were slope, intercept, reaction time, measured in milliseconds, and accuracy, indicated by a number between 0 and 1 , with 0 indicating that the answer was false and 1 indicating that the answer was right. The electrophysiological-dependent measures were the amplitude and latency of the P150, N200, P3a and P3b ERP components.

VVLT: This task is an adapted version of RAVLT (Lezak, 1995). The VVLT was used to measure episodic memory. It included 30 words, 12 of which are positive, 12 of which are negative and six of which are neutral, as determined by the valence ratings of word lists by a pool of healthy volunteers (Klaassen et al., 2002). These words were presented on a computer screen three times in a row, each time followed by immediate free recall of all remembered words. After 30 minutes, participants were subjected to a delayed recall test and a recognition test. During the latter, 30 words were presented, 15 of which were previously presented and another 15 that were new. The outcome measures of the immediate and delayed recall tests were hits (correctly recalled words), false alarms (words named that were not on the list) and doubles (words named twice). In addition, performance was assessed taking into account the valence of the words, by taking the same measures for each of the valence categories separately.

The behavioural-dependent measures of the recognition test were reaction time, measured in milliseconds, accuracy, indicated by a number between 0 and 1, with 0 indicating that the answer was false and 1 indicating that the answer was right and sensitivity $\left(A^{\prime}\right) . A^{\prime}$ is calculated as follows: $A^{\prime}=$ $1-1 / 4[f r / c r+(1-c r) /(1-f r)]$, where $f r$ is falsely recognized words and $\mathrm{cr}$ is correctly recognized words. The electrophysiological dependent measures were the amplitude and latency of the P150, N200, P3a and P3b ERP components.

Electroencephalography: The electroencephalogram was recorded using 32 electrodes attached to a cap according to the international 10-20 system (Jasper, 1958). The ground electrode was placed on the AFz location, on the forehead. An electrode placed at the left mastoid served as a reference. An electro-oculogram (EOG) was measured bipolarly vertically above and below the right eye and horizontally next to the right and the left eye.

Data were sampled at $1000 \mathrm{~Hz}$ and filtered online between 0.05 and $100 \mathrm{~Hz}$. Offline, data were screened for artefacts and filtered between 1 and $30 \mathrm{~Hz}$. ERPs were extracted by stimulus-locked averaging of epochs from $100 \mathrm{~ms}$ before to $1000 \mathrm{~ms}$ after stimulus presentation.

For both tasks, ERPs were analysed at Fz, FCz, Cz, CPz, $\mathrm{Pz}, \mathrm{P} 3$ and P4. In the ERPs extracted from the electroencephalogram during the SMS, five peaks could be discerned. P150 was determined as the highest amplitude within $110-210 \mathrm{~ms}$ after stimulus onset and N200 as the lowest amplitude within 180-300 ms after stimulus onset. P3a and P3b were determined as the highest amplitude within windows individually specified for each participant. The windows for P3a and P3b were not overlapping and had to be between 260 and $430 \mathrm{~ms}$ after stimulus onset. In addition, the latencies of these four peaks were included in the analysis. 
In the VVLT, the same components were observed. P150 was determined as the highest amplitude within a window of $130-210 \mathrm{~ms}$ after stimulus onset, N200 as the lowest amplitude within 180-260 ms after stimulus onset and P3a and P3b were again determined as the highest amplitude within windows individually specified for each participant. The windows for P3a and P3b were chosen such that they would not overlap and fell between 230 and $420 \mathrm{~ms}$ after stimulus onset. The latencies of these four peaks were included in the analysis.

Statistical analysis: All behavioural and ERP data were analysed by means of repeated measures analysis of variance (ANOVA) with the within-subjects factor treatment, which had two levels: PLA and TPD. Additional within-subject factors were electrode position (five levels), workload (three levels: one, two and four letters memorized) and stimulus type (two levels: old and new) for the SMS. For the VVLT, additional variables were electrode position (five levels), trial (three levels: trial 1,2 and 3) and valence (three levels: positive, negative and neutral) for the immediate recall part and stimulus type (two levels: old and new) for the recognition part. Behavioural data, including reaction time and accuracy, and ERP data, including amplitudes and latencies, were tested for the main effects and all possible interaction effects. The effects were evaluated using the Greenhouse-Geisser correction and were considered significant at $p<0.05$. Where necessary the Bonferroni correction was applied. In the case of a significant main effect, post hoc pairwise comparisons were conducted. Interaction effects were analysed post hoc by conducting additional repeated measures ANOVAs, including only those factors that were involved in the interaction.

\section{Results}

\section{Blood samples}

After TPD, the plasma tyrosine and phenylalanine level was significantly reduced by $57 \%$ at $\mathrm{T} 7$, compared to $\mathrm{T} 0\left(F_{1,13}=\right.$ 131.161, $p<0.001)$ and the tyrosine and phenylalanine/ $\Sigma$ LNAA ratio was reduced by $62 \%$ at $\mathrm{T} 7\left(F_{1,13}=108.134\right.$, $p<0.001)$. The Tyrosine and phenylalanine level was increased by $61 \%$ at $\mathrm{T} 7$ compared to the baseline $\left(F_{1,15}=24.150, p<0.001\right)$ in the PLA condition and the tyrosine and phenylalanine/ $\Sigma$ LNAA ratio was increased by $40 \%$ at $\mathrm{T} 7\left(F_{1,15}=21.992, p<0.001\right)$.

\section{Questionnaires}

Neither the VAS nor the complaint list showed significant differences between the PLA and TPD conditions $\left(F_{s}<1.391\right)$.

\section{SMS}

Task performance: The behavioural measures slope, intercept, reaction time and accuracy were not affected by the treatments (see Table 1). However, TPD appeared to speed up the reaction time $\left(F_{1,16}=3.995, p=0.063\right)$, although this effect did not reach significance.
Table 1. Mean scores for dependent variables of the SMS after PLA and TPD

\begin{tabular}{lll}
\hline & \multicolumn{2}{l}{ Mean (SEM) scores } \\
\cline { 2 - 3 } & PLA & TPD \\
\hline Reaction time (ms) & $472(12)$ & $460(11)$ \\
Accuracy & $0.96(0.01)$ & $0.96(0.01)$ \\
Slope (ms/letter) & $41(3)$ & $37(3)$ \\
Intercept (ms) & $417(11)$ & $410(9)$ \\
\hline
\end{tabular}

To evaluate whether the task worked appropriately, the effects of workload and stimulus type on reaction time and accuracy were analysed. The reaction time increased as workload increased $\left(F_{1.35,21.64}=202.805, p<0.001\right)$ and reaction time was longer for new as compared to old items $\left(F_{1,16}=71.148, p<0.001\right)$.

ERP measures: Figure 1 depicts the grand average ERPs per treatment condition and task manipulation at $\mathrm{Cz}$. The ERP latencies and amplitudes were analysed using repeated measures ANOVA with treatment, electrode position, workload and stimulus type as within-subjects factors. Upon inspection of the main effects of workload and stimulus type, we learned that the task produced the expected effects on the ERPs. For instance, P3a amplitude decreased with increasing workload $\left(F_{1.56,24.94}=20.790, p<0.001\right)$.

The relationship between treatment and the amplitude and latency of the ERP components is plotted in Figure 2. Treatment affected the amplitude and latency of several components. There was no significant main effect of the treatment on P150 amplitude or latency. N200 was delayed after TPD $\left(F_{1,16}=4.911, p<0.05\right)$, as compared to PLA. TPD decreased P3a amplitude, as compared to PLA $\left(F_{1,16}=5.715, p<0.05\right)$. Furthermore, analysis of the $\mathrm{P} 3 \mathrm{a}$ latency revealed an interaction between treatment, workload and stimulus type $\left(F_{1.97,31.56}=6.473, p<0.01\right)$. The post hoc analysis did not reveal any significant effects of treatment. For P3b latency, an interaction between the treatment and electrode position was found $\left(F_{2.41,38.53}=3.398, p<0.05\right)$. The post hoc analysis revealed that at the $\mathrm{Fz}$ electrode, $\mathrm{P} 3 \mathrm{~b}$ latency was increased by $\operatorname{TPD}\left(F_{1,16}=5.229, p<0.05\right)$.

\section{VVLT}

Task performance: Immediate recall scores and delayed recall scores are listed in Table 2.

The hit rate in the immediate recall phase of the VVLT was not affected by the treatment. However, TPD reduced false alarms and doubles (false alarm: $F_{1,16}=6.272$, $p<0.05$; doubles: $\left.F_{1,16}=7.385, p<0.05\right)$. The hit rate significantly increased over the trials $\left(F_{1.67,26.75}=170.913, p<0.01\right)$, as should be expected. Neither delayed recall (see Table 2, $F_{s}<1.595$ for hits, false alarms and doubles) nor recognition (see Table 3, $F_{s}<1.358$ for accuracy, RT and $A^{\prime}$ ) were affected by the treatment. However, accuracy was lower when an old item was presented compared to when a new item was presented in the recognition test 


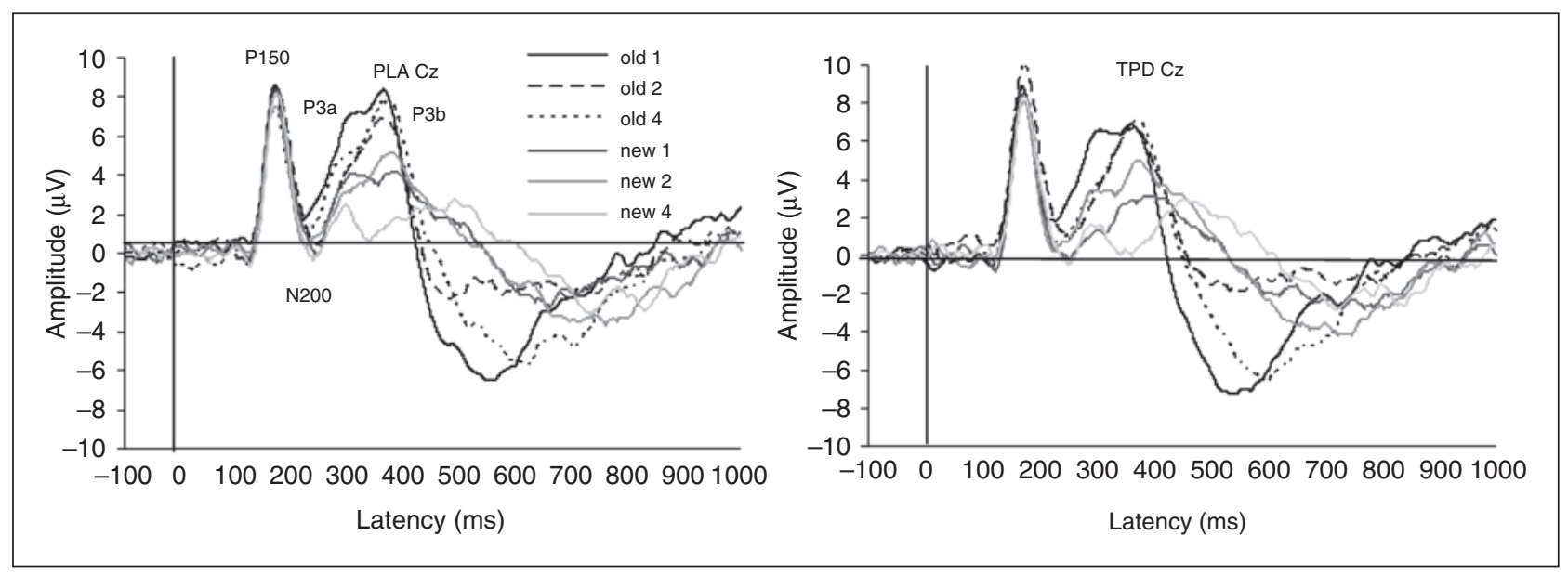

Figure 1. Grand average ERPs during the SMS, corresponding to the six combinations of workload and stimulus types (workload 1, 2 and 4 and old versus new stimuli), for Cz. Treatment conditions are depicted in separate plots (left: PLA, right: TPD).

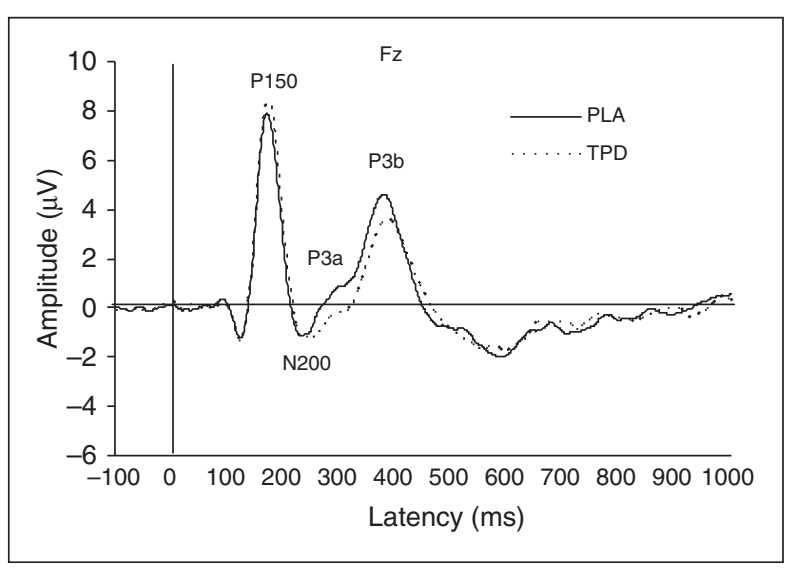

Figure 2. Grand average ERPs during the SMS after PLA and TPD at Fz.

$\left(F_{1,16}=7.264, p<0.05\right)$. The valence of the words did not affect memory performance.

ERP measures: Grand average ERPs, averaged over the trials, after PLA and TPD, are shown in Figure 3. A repeated measures ANOVA with treatment and electrode position as within-subjects factors was run on these data. P150 latency was increased after TPD compared to PLA $\left(F_{1,16}=6.610, p<0.05\right)$. For N200 amplitude, an interaction between the treatment and electrode position was found $\left(F_{1.92,30.66}=5.448, p<0.05\right)$. The post hoc analysis revealed that the amplitude was different over different electrode positions for the PLA condition, but there was no clear pattern. P3b latency was delayed after TPD as compared to PLA $\left(F_{1,16}=6.398, p<0.05\right)$. Furthermore, there was an interaction between the treatment and electrode position $\left(F_{2.32,40.37}=2.788, p<0.05\right)$. The post hoc analysis showed that the latency increasing effect of TPD was significant on the $\mathrm{FCz}$ and $\mathrm{Cz}$ electrode positions.

Figure 4 depicts the grand average ERPs measured during recognition testing after PLA and TPD. ERP amplitudes and latencies were again analysed using a repeated measures ANOVA with treatment (PLA and TPD) and stimulus type (old and new) as within-subjects factors. This analysis revealed that $\mathrm{P} 150$ was not altered by TPD, nor were any main effects of treatment observed for the N200 component. As for the latency data, however, an interaction between the treatment and the stimulus type was found $\left(F_{1,16}=8.278\right.$, $p<0.05$ ), which indicated that N200 latency decreased after TPD when an old item was presented

P3a latency was decreased after TPD as compared to PLA $\left(F_{1,16}=6.868, p<0.05\right)$.

\section{Discussion}

This is the first study that investigated the effects of dopamine depletion on working memory and episodic memory, as well as their electrophysiological correlates. After TPD, the tyrosine and phenylalanine/ $\Sigma$ LNAA ratio was decreased by $62 \%$. This is a significant level of depletion and similar to previous studies using the same method (Grevet et al., 2002; Harrison et al., 2004).

TPD did not significantly affect working memory performance, but did have some effects on episodic memory, as was indicated by a decreased false alarm rate and a decrease in the double mentioning of words. During the performance of a working memory task, TPD delayed N200 latency, decreased P3a amplitude and increased P3b latency.

After TPD, both P150 and P3b latency were increased during episodic memory encoding. During the recognition phase, TPD decreased P3a latency. Accordingly, the hypothesis that TPD would interfere with working memory was not confirmed by the behavioural data. The hypothesis that TPD would negatively affect episodic memory was even disconfirmed by the behavioural data, since fewer false alarms and doubles were observed after TPD. On the other hand, the effects observed on ERPs suggest that there was a memory modulating effect of TPD. It is suggested that these effects were too small to be detected in the behavioural data.

Previous studies showed conflicting results with respect to the effect of TPD on working memory (Ellis et al., 2007; 
Table 2. Means of percentages of hits, false alarms and doubles of the VVLT after PLA and TPD

\begin{tabular}{|c|c|c|c|c|c|c|}
\hline & \multicolumn{6}{|c|}{ Mean (SEM) of percentages of words recalled } \\
\hline & \multicolumn{3}{|l|}{ PLA } & \multicolumn{3}{|l|}{ TPD } \\
\hline & Hits & False alarms & Doubles & Hits & False alarms & Doubles \\
\hline Immediate recall & $55.6(2.4)$ & $1.7(0.5)$ & $4.6(0.8)$ & $52.9(2.9)$ & $0.7(0.2)$ & $2.5(0.4)$ \\
\hline Delayed recall & $61.6(3.7)$ & $2.4(0.8)$ & $2.9(0.7)$ & $57.3(4.3)$ & $1.8(0.6)$ & $1.8(0.6)$ \\
\hline Immediate recall - positive words & $56.9(3.2)$ & & $3.8(1.1)$ & $53.6(2.8)$ & & $1.8(0.5)$ \\
\hline Immediate recall - negative words & $53.8(3.1)$ & & $4.1(0.8)$ & $52.6(3.7)$ & & $3.1(0.7)$ \\
\hline Immediate recall - neutral words & $57.2(3.6)$ & & $5.6(1.3)$ & $52.0(4.2)$ & & $2.6(1.4)$ \\
\hline Delayed recall - positive words & $20.3(1.6)$ & & $0.7(0.4)$ & $19.6(1.3)$ & & $1.1(0.3)$ \\
\hline Delayed recall - negative words & $19.8(1.3)$ & & $1.1(0.4)$ & $18.3(1.8)$ & & $0.3(0.2)$ \\
\hline Delayed recall - neutral words & $22.5(1.7)$ & & $1.0(0.7)$ & $19.6(2.0)$ & & $0.0(0.0)$ \\
\hline
\end{tabular}

Table 3. Mean reaction time, accuracy and sensitivity of the VVLT, recognition test after PLA and TPD

\begin{tabular}{lll}
\hline & \multicolumn{2}{l}{ Mean (SEM) scores } \\
\cline { 2 - 3 } & PLA & TPD \\
\hline Reaction time (ms) & $749(23)$ & $738(21)$ \\
Accuracy & $0.91(0.02)$ & $0.89(0.02)$ \\
Sensitivity $\left(A^{\prime}\right)$ & $0.95(0.01)$ & $0.94(0.01)$ \\
\hline
\end{tabular}

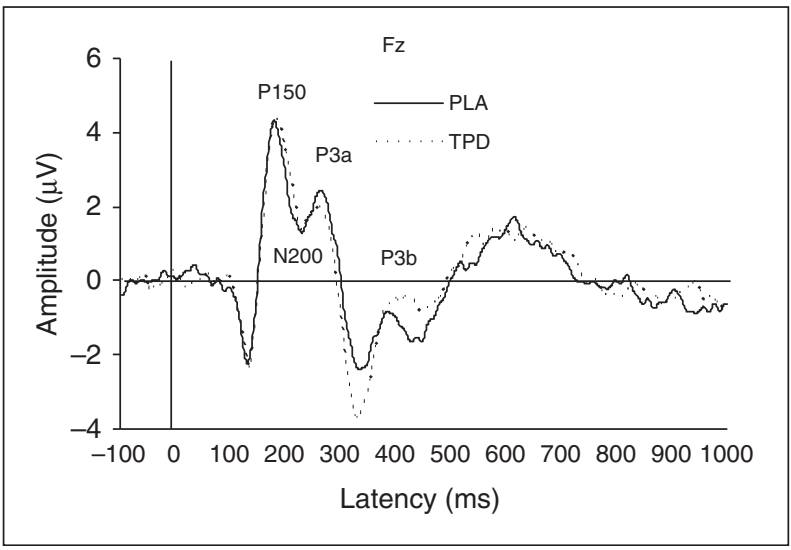

Figure 3. Grand averages during the encoding phase of the VVLT after PLA and TPD at Fz.

Gijsman et al., 2002; Harmer et al., 2001; Harrison et al., 2004; Lythe et al., 2005; Mehta et al., 2005a; Nathan et al., 2002). A satisfying explanation for this inconsistency has not yet been given. In this study, the lack of behavioural effects could not be attributed to a lack of depletion. Furthermore, both behavioural and ERP measures of the working memory task showed the expected variations between the different task conditions (Pelosi et al., 1995). It is important to note that the PLA condition in this study involves the administration of a balanced amino acid mixture, which led to a $40 \%$ increase in the tyrosine and phenylalanine/ $\Sigma$ LNAA ratio. It is not clear how this may have affected the results, but for future studies the inclusion of baseline testing may be considered.

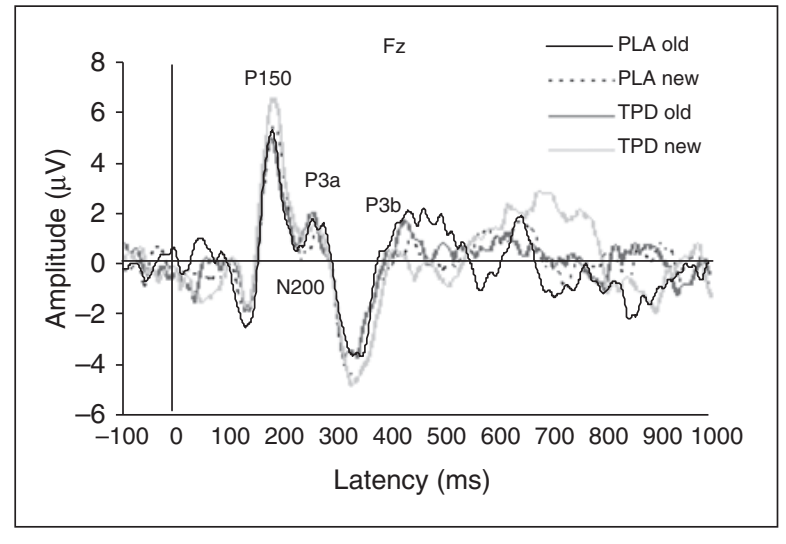

Figure 4. Grand average ERPs during the recognition test of the VVLT after PLA and TPD at presentation of old and new items at Fz.

Furthermore, it is important to note that previous studies used other working memory tests than the one used in the present study. It is highly likely that dopamine has differential effects on different forms of working memory. However, even among studies using comparable tasks, there were some that found an effect of TPD, whereas others did not. It has therefore been proposed that although TPD does alter dopaminergic transmission, its effect may not be large enough to consistently alter neuropsychological function (Lythe et al., 2005). With respect to the present data, this may be a valid suggestion, since we found no effects on behavioural measures, even though changes in the ERPs were observed.

The effects of TPD on ERP measures indicate that TPD altered brain processes, which are possibly related to memory function. TPD delayed N200 latency. N200 amplitude has been linked to response inhibition or conflict (Bokura et al., 2001; Falkenstein et al., 1995; Forster and Pavone, 2008). Increased latency possibly reflects the prolonged duration or delayed onset of response conflict. Alternatively, the current finding may indicate increased response selection time after the depletion of tyrosine and phenylalanine, since N200 latency has also previously been related to the timing of response selection (Gajewski et al., 2008).

TPD decreased P3a amplitude. P3a is considered a novelty related peak, where increased amplitude most likely reflects an alerting effect of the novel stimulus (Coull, 1998). 
Decreased P3a amplitude, therefore, may indicate decreased alertness. This may be attributed either to a decrease in dopamine levels after TPD or an increase of dopamine levels after the PLA condition. Indeed, Grevet et al. (2002) reported increased subjective alertness ratings after consumption of the balanced amino acid mixture as compared to the baseline. P3b latency was increased by TPD. Since P3b latency is known to increase when categorization of the stimulus is made more difficult by degrading the stimulus or when memory set size increases (Garcia-Larrea and Cezanne-Bert, 1998; Smulders et al., 1995), it can be inferred that the stimulus categorization effect was increased by TPD.

Together, the described effects suggest that TPD affected stimulus processing during working memory. However, since no effects were observed on behavioural measures it is suggested that effects of TPD are not large enough to affect performance. This idea is supported by findings from other studies (Ellis et al., 2007; Mehta et al., 2005a).

Episodic memory was not impaired by TPD. However, after TPD fewer false alarms and doubles were observed in the immediate recall phase. A decrease in false alarms has also been observed after 5-HT suppletion, whereas false alarms have been shown to increase after serotonin depletion (Meeter et al., 2006). These contrasting effects are in line with the idea that dopamine and serotonin have opposing influences on working memory (Luciana et al., 1998). The hit rate and the false alarm rate (taking together false alarms and doubles) were combined post hoc in a sensitivity measure $\left(A^{\prime}\right)$ using the same formula as used in the recognition test. This measure indicated an increase in sensitivity after TPD $\left(A^{\prime}=0.572\right.$ in the PLA condition and $A^{\prime}=0.753$ after TPD). This further supports the idea that dopamine and serotonin have opposing influences, since sensitivity has been observed to decrease after serotonin depletion (Schmitt et al., 2000).

The finding that TPD did not negatively affect performance on the word-learning test is at odds with the findings of Grevet et al. (2002), who found decreased performance on delayed recall as assessed in RAVLT after TPD. However, our findings are consistent with those of Harrison et al. (2004), who found no effect of TPD on a 15-word VVLT. Although this has not been tested explicitly, it may be possible that TPD exerts larger effects on auditory word learning compared to visual word learning.

On the recognition task there was no effect of TPD. The lack of memory impairing effects of TPD could not be explained by the ineffectiveness of the task, since, as expected, the hit rate in the immediate recall test increased over the trials, and accuracy on the recognition task was lower for old, as compared to new, items.

It was expected that TPD and PLA would differentially affect responses to positive and negative words (McLean et al., 2004; Vrshek-Schallhorn et al., 2006). However, this was not the case. Perhaps differences between positive and negative words can only be observed when a response has to be made immediately after the appearance of the stimulus (as is the case in the Go/No-Go task (McLean et al., 2004)) and not when there is a delay between stimulus presentation and testing.

ERPs recorded during the encoding phase of this episodic memory task revealed that TPD delayed the latency of both
P150 and P3b ERP components. P150 is, in addition to working memory, also thought to be related to stimulus categorization (Schendan et al., 1998). Although in the VVLT no categorization is necessary, encoding may be regarded similarly to categorization. Delayed P150 latency may reflect a delay in this process. This is in line with the effect on P3b latency, since P3b is known to be dependent on stimulus categorization time (Luck, 2005), or in this case, encoding time. A delay in encoding therefore may lead to a delay in P3b latency.

During recognition testing, P3a latency was decreased by TPD. As explained above, P3a amplitude is thought to be related to alertness or novelty (Coull, 1998). An effect on latency is therefore more difficult to explain.

In summary, TPD did not affect episodic memory performance. Participants even produced fewer false alarms and reported fewer words two times in the immediate recall phase. On the ERPs, however, some effects were observed that were indicative of adverse effects of TPD on memory. Since an effect of TPD on word learning was found previously (Grevet et al., 2002) and electrophysiological correlates of memory were affected by TPD in the present study, it is suggested that the effects of TPD did affect memory processing, but that the effects on memory performance remained sub threshold.

In conclusion, the current findings suggest that TPD, which lowers dopamine levels, affects memory-related processing. Dopamine is likely to be involved both in working memory and episodic memory. This has implications for the study of memory. Where previously the focus has been on other neurotransmitters, such as acetylcholine and serotonin, it has now become clear that dopamine also deserves attention. Future studies may further improve the study design in order to produce more sizeable effects.

\section{Acknowledgements}

We would like to thank Daniel Mendelsohn, Joep Wolters and Philip Swerts for helping in data acquisition. This study was entirely paid for and carried out at Maastricht University. WJR is also employed by Hoffman-LaRoche R\&D, Basel, Switzerland, while remaining affiliated to Maastricht University. This raises no conflict of interest. At times during the study, A Sambeth received support from the Netherlands Organization of Scientific Research (VENI grant 451-07-011).

\section{References}

Barrett SP, Leyton M (2004) Acute phenylalanine/tyrosine depletion: A new method to study the role of catecholamines in psychiatric disorders. Primary Psychiatry 11: 37-41.

Bokura H, Yamaguchi S, Kobayashi S (2001) Electrophysiological correlates for response inhibition in a Go/NoGo task. Clin Neurophysiol 112: 2224-2232.

Bongiovanni R, Newbould E, Jaskiw GE (2008) Tyrosine depletion lowers dopamine synthesis and desipramine-induced prefrontal cortex catecholamine levels. Brain Res 1190: 39-48.

Cools R, Robbins TW (2004) Chemistry of the adaptive mind. Philos T Roy Soc A 362: 2871-2888.

Costa A, Peppe A, Dell'Agnello G, et al. (2003) Dopaminergic modulation of visual-spatial working memory in Parkinson's disease. Dement Geriatr Cogn 15: 55-66. 
Coull JT (1998) Neural correlates of attention and arousal: Insights from electrophysiology, functional neuroimaging and psychopharmacology. Prog Neurobiol 55: 343-361.

Ellenbogen MA, Young SN, Dean P, Palmour RM, Benkelfat C (1996) Mood response to acute tryptophan depletion in healthy volunteers: Sex differences and temporal stability. Neuropsychopharmacology 15: 465-474.

Elliott R, Sahakian BJ, Matthews K, Bannerjea A, Rimmer J, Robbins TW (1997) Effects of methylphenidate on spatial working memory and planning in healthy young adults. Psychopharmacology (Berlin) 131: 196-206.

Ellis KA, Mehta MA, Naga Venkatesha Murthy PJ, McTavish SF, Nathan J, Grasby PM (2007) Tyrosine depletion alters cortical and limbic blood flow but does not modulate spatial working memory performance or task-related blood flow in humans. Hum Brain Mapp 28: 1136-1149.

Falkenstein M, Koshlykova NA, Kiroj VN, Hoormann J, Hohnsbein J (1995) Late ERP components in visual and auditory Go/Nogo tasks. Electroen Clin Neuro 96: 36-43.

Farber DA, Beteleva TG, Ignat'eva IS (2004) Functional organization of the brain during the operation of the working memory. Fiziologiia Cheloveka 30: 5-12.

Forster B, Pavone EF (2008) Electrophysiological correlates of crossmodal visual distractor congruency effects: evidence for response conflict. Cognitive Affective and Behavioral Neuroscience 8: 65-73.

Gajewski PD, Stoerig P, Falkenstein M (2008) ERP - correlates of response selection in a response conflict paradigm. Brain Res 1189: 127-134.

Garcia-Larrea L, Cezanne-Bert G (1998) P3, positive slow wave and working memory load: a study on the functional correlates of slow wave activity. Electroen Clin Neuro 108: 260-273.

Gijsman HJ, Scarna A, Harmer CJ, et al. (2002) A dose-finding study on the effects of branch chain amino acids on surrogate markers of brain dopamine function. Psychopharmacology (Berlin) 160: 192-197.

Grevet EH, Tietzmann MR, Shansis FM, et al. (2002) Behavioural effects of acute phenylalanine and tyrosine depletion in healthy male volunteers. $J$ Psychopharmacol 16: 51-55.

Harmer CJ, McTavish SF, Clark L, Goodwin GM, Cowen PJ (2001) Tyrosine depletion attenuates dopamine function in healthy volunteers. Psychopharmacology (Berlin) 154: 105-111.

Harrison BJ, Olver JS, Norman TR, Burrows GD, Wesnes KA, Nathan PJ (2004) Selective effects of acute serotonin and catecholamine depletion on memory in healthy women. $J$ Psychopharmacol 18: 32-40.

Jasper HH (1958) The ten-twenty electrode system of the International Federation. Electroen Clin Neuro 10: 370-375.

Klaassen T, Riedel WJ, Deutz NE, Van Praag HM (2002) Mood congruent memory bias induced by tryptophan depletion. Psychol Med 32: 167-172.

Le Masurier M, Cowen PJ, Sharp T (2004a) Fos immunocytochemical studies on the neuroanatomical sites of action of acute tyrosine depletion in the rat brain. Psychopharmacology (Berlin) 171: 435-440.

Le Masurier M, Houston G, Cowen P, Grasby TS, Hume S (2004b) Tyrosine-free amino acid mixture attenuates amphetamineinduced displacement of [11C]raclopride in striatum in vivo: a rat PET study. Synapse 51: 151-157.

Lewis SJ, Slabosz A, Robbins TW, Barker RA, Owen AM (2005) Dopaminergic basis for deficits in working memory but not attentional set-shifting in Parkinson's disease. Neuropsychologia 43: 823-832.

Leyton M, Dagher A, Boileau I, et al. (2004) Decreasing amphetamine-induced dopamine release by acute phenylalanine/tyrosine depletion: a PET/[11C]raclopride study in healthy men. Neuropsychopharmacology 29: 427-432.
Leyton M, Young SN, Pihl RO, et al. (2000) Effects on mood of acute phenylalanine/tyrosine depletion in healthy women. Neuropsychopharmacology 22: 52-63.

Lezak MD (1995) Neuropsychological Assessment. New York: Oxford University Press.

Luciana M, Collins PF (1997) Dopaminergic modulation of working memory for spatial but not object cues in normal humans. J Cognitive Neurosci 9: 330-347.

Luciana M, Collins PF, Depue RA (1998) Opposing roles for dopamine and serotonin in the modulation of human spatial working memory functions. Cereb Cortex 8: 218-226.

Luciana M, Depue RA, Arbisi P, Leon A (1992) Facilitation of working memory in humans by a $\mathrm{d} 2$ dopamine receptor agonist. J Cognitive Neurosci 4: 58-68.

Luck SJ (2005) An Introduction to the Event-related Potential Technique. Cambridge, MA: The MIT Press.

Lythe KE, Anderson IM, Deakin JF, Elliott R, Strickland PL (2005) Lack of behavioural effects after acute tyrosine depletion in healthy volunteers. $J$ Psychopharmacol 19: 5-11.

Matrenza C, Hughes JM, Kemp AH, Wesnes KA, Harrison BJ, Nathan PJ (2004) Simultaneous depletion of serotonin and catecholamines impairs sustained attention in healthy female subjects without affecting learning and memory. J Psychopharmacol 18: $21-31$.

McLean A, Rubinsztein JS, Robbins TW, Sahakian BJ (2004) The effects of tyrosine depletion in normal healthy volunteers: implications for unipolar depression. Psychopharmacology (Berlin) 171: 286-297.

McTavish SF, Cowen PJ, Sharp T (1999) Effect of a tyrosine-free amino acid mixture on regional brain catecholamine synthesis and release. Psychopharmacology (Berlin) 141: 182-188.

McTavish SF, McPherson MH, Harmer CJ, et al. (2001) Antidopaminergic effects of dietary tyrosine depletion in healthy subjects and patients with manic illness. Brit J Psychiat 179: 356-360.

Meeter M, Talamini L, Schmitt JA, Riedel WJ (2006) Effects of 5-HT on memory and the hippocampus: model and data. Neuropsychopharmacology 31: 712-720.

Mehta MA, Gumaste D, Montgomery AJ, McTavish SF, Grasby PM (2005a) The effects of acute tyrosine and phenylalanine depletion on spatial working memory and planning in healthy volunteers are predicted by changes in striatal dopamine levels. Psychopharmacology (Berlin) 180: 654-663.

Mehta MA, Hinton EC, Montgomery AJ, Bantick RA, Grasby PM (2005b) Sulpiride and mnemonic function: effects of a dopamine D2 receptor antagonist on working memory, emotional memory and long-term memory in healthy volunteers. $J$ Psychopharmacol 19: 29-38.

Mehta MA, Sahakian BJ, McKenna PJ, Robbins TW (1999) Systemic sulpiride in young adult volunteers simulates the profile of cognitive deficits in Parkinson's disease. Psychopharmacology (Berlin) 146: 162-174.

Montgomery AJ, McTavish SF, Cowen PJ, Grasby PM (2003) Reduction of brain dopamine concentration with dietary tyrosine plus phenylalanine depletion: an [11C]raclopride PET study. Am J Psychiat 160: 1887-1889.

Moustafa AA, Sherman SJ, Frank MJ (2008) A dopaminergic basis for working memory, learning and attentional shifting in Parkinsonism. Neuropsychologia 46: 3144-3156.

Nathan PJ, Harrison BJ, Olver JS, Norman TR, Burrows GD, Stough C (2002) Depletion of serotonin versus dopamine produces double dissociation on tests of mnemonic function in healthy volunteers. Int J Neuropsychop 5(Suppl 1): S191.

Nieoullon A (2002) Dopamine and the regulation of cognition and attention. Prog Neurobiol 67: 53-83. 
Owen AM, Iddon JL, Hodges JR, Summers BA, Robbins TW (1997) Spatial and non-spatial working memory at different stages of Parkinson's disease. Neuropsychologia 35: 519-532.

Pelosi L, Hayward M, Blumhardt LD (1995) Is 'memory-scanning' time in the Sternberg paradigm reflected in the latency of eventrelated potentials? Electroen Clin Neuro 96: 44-55.

Prasher D, Findley L (1991) Dopaminergic induced changes in cognitive and motor processing in Parkinson's disease: an electrophysiological investigation. $J$ Neurol Neurosur Ps 54: 603-609.

Roiser JP, McLean A, Ogilvie AD, et al. (2005) The subjective and cognitive effects of acute phenylalanine and tyrosine depletion in patients recovered from depression. Neuropsychopharmacology 30: 775-785.

Ruhe HG, Mason NS, Schene AH (2007) Mood is indirectly related to serotonin, norepinephrine and dopamine levels in humans: a meta-analysis of monoamine depletion studies. Mol Psychiatr 12: 331-359.

Schendan HE, Ganis G, Kutas M (1998) Neurophysiological evidence for visual perceptual categorization of words and faces within $150 \mathrm{~ms}$. Psychophysiology 35: 240-251.

Schmitt JA, Jorissen BL, Sobczak S, et al. (2000) Tryptophan depletion impairs memory consolidation but improves focussed attention in healthy young volunteers. J Psychopharmacol 14: $21-29$.
Smulders FT, Kok A, Kenemans JL, Bashore TR (1995) The temporal selectivity of additive factor effects on the reaction process revealed in ERP component latencies. ACTA Psychologica (Amsterdam) 90: 97-109.

Stanzione P, Fattapposta F, Giunti P, et al. (1991) P300 variations in Parkinsonian patients before and during dopaminergic monotherapy: a suggested dopamine component in P300. Electroen Clin Neuro 80: 446-453.

Sternberg S (1966) High-speed scanning in human memory. Science 153: 652-654.

van Eijk HM, Rooyakkers DR, Deutz NE (1993) Rapid routine determination of amino acids in plasma by high-performance liquid chromatography with a 2-3 microns Spherisorb ODS II column. J Chromatogr 620: 143-148.

van Ruitenbeek P, Sambeth A, Vermeeren A, Young SN, Riedel WJ (2009) Effects of L-histidine depletion and tyrosine/phenylalanine depletion on sensory and motor processes in healthy volunteers. Brit J Pharmacol 157: 92-103.

Vrshek-Schallhorn S, Wahlstrom D, Benolkin K, White T, Luciana M (2006) Affective bias and response modulation following tyrosine depletion in healthy adults. Neuropsychopharmacol 31: $2523-2536$.

Young SN, Smith SE, Pihl RO, Ervin FR (1985) Tryptophan depletion causes a rapid lowering of mood in normal males. Psychopharmacology (Berlin) 87: 173-177. 